\title{
Analysis of Granules Behavior in Continuous Drum Mixer by DEM
}

\author{
Rikio SODA, ${ }^{11}$ Akira SATO, ${ }^{11}$ Junya KANO, ${ }^{1)}$ Eiki KASAI, ${ }^{1)}$ Fumio SAITO, ${ }^{11}$ Masaki HARA ${ }^{21}$ and \\ Takazo KAWAGUCHI'
}

1) Institute of Multidisciplinary Research for Advanced Materials, Tohoku University, 2-1-1 Katahira, Aoba-ku, Sendai $980-8577$ Japan. $\quad 2$ 2) Corporate Research \& Development Laboratories, Sumitomo Metals Industries, Ltd., 16-1 Sunayama, Kashima, Ibaraki 314-0255 Japan.

(Received on November 5, 2008; accepted on January 15, 2009)

\begin{abstract}
A numerical simulation model was developed to analyze the behavior of iron ore granules in a continuous drum mixer by Discrete Element Method (DEM). The effects of the gradient angle of the drum mixer on the behavior of granules were investigated using the simulation. The granulation experiment of iron ore fine was also performed to observe the occupation ratio and retention time. The occupation ratio and retention time obtained by both the simulation and experiment decrease with an increase in the gradient angle. The effect of the length of the drum mixer on the behavior of granules was investigated using the DEM simulation. The retention time increases with an increase in the length of the drum mixer. If the occupation distributions in the direction of the rotational axis is based on the exit of the drum mixer, it will be the same regardless of the length of the drum mixer. This simulation model proposed will be useful to understand granules behavior and to design of granulators.
\end{abstract}

KEY WORDS: granulation; iron ore; continuous drum mixer; discrete element method.

\section{Introduction}

The granulation of iron ore is an important process in the iron ore sintering, which supplies main iron burden to the blast furnace for ironmaking. It strongly affects the productivity and properties of produced sinter such as strength and reducibility. Since recent rapid increase in the world steel production has accelerated the deterioration of composition and property of iron ore, importance of the granulation process grown significantly. In general, the granulation is made by using a drum mixer or pan pelletizer with adding sprayed water to the mixture of fine iron ore and fluxing materials such as limestone and burnt lime. In order to properly control the granulation process, it is necessary to understand the motion of the materials in the mixer/granulator. Several studies have performed so far to predict granulation growth rate theoretically ${ }^{1-4)}$ and experimentally. ${ }^{5-8)}$ In addition, the effects of rotational speed and particles charge ratio on the movement of particles have been investigated theoretically. ${ }^{9,10)}$ However the granulation phenomenon is not yet understood fully because it is very complicated and there are lots of parameters related to the granulation phenomenon such as a rotational speed of drum mixer, diameter of drum mixer, length of drum mixer, gradient angle and so on.

Since the computer simulation has a possibility to provide significant information in detail on granulation process, we have tried to develop the simulation model of granules behavior the batch type drum mixer ${ }^{11)}$ using Discrete Element Method (DEM). ${ }^{12-14)}$

This paper describes the numerical simulation method for the motion of the granules in a continuous drum mixer by using DEM and its validity is discussed in term of the occupation ratio and retention time. The effects of drum length and angle on the behavior of granules are also examined.

\section{Simulation of Granules Behavior}

\subsection{Discrete Element Method (DEM)}

The granules behavior in the continuous drum mixer simulated by Discrete Element Method (DEM), which is one of the most reliable and popular computer simulation methods for particles behavior. ${ }^{15-23)}$ The interaction forces in collision between two particles are represented by the Voigt model as shown in Fig. 1, which is composed of a spring-dashpot and a slider for the friction in the tangential motion.

\subsection{Modeling of Granules}

Prior to applying the DEM to granulation process, the

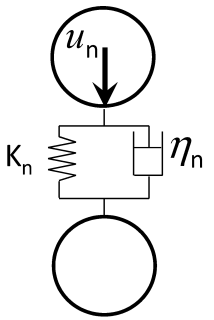

(a) Normal Force

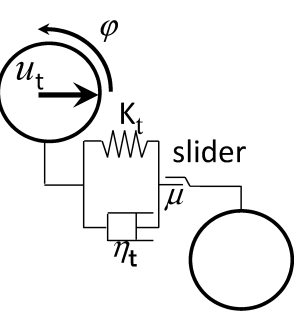

(b) Tangential Force
Fig. 1. Principle of the simulation model. 
Table 1. Simulation conditions.

\begin{tabular}{l|ll}
\hline \multirow{3}{*}{ Simulation } & Time step & $2 \times 10^{-4} \mathrm{~s}$ \\
& Frictional coefficient & 0.7 \\
& Rolling friction & 1.88 \\
\hline & Particle diameter & $10 \mathrm{~mm}$ \\
& Density & $3.2 \mathrm{~g} / \mathrm{cm}^{3}$ \\
& Young's modulus & $2.2 \times 10^{6} \mathrm{~Pa}$ \\
& Poisson ratio & 0.3 \\
\hline
\end{tabular}

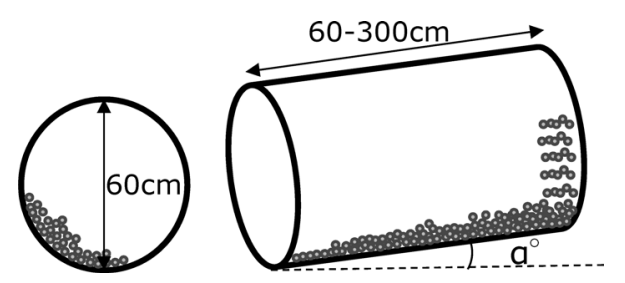

Fig. 2. Schematic diagram of continuous drum mixer used in the simulation.

Table 2. Condition of drum mixer.

\begin{tabular}{l|l}
\hline Diameter & $60 \mathrm{~cm}$ \\
Length & $60,120,240,300 \mathrm{~cm}$ \\
Rotational speed & $20 \mathrm{rpm}$ \\
Gradient angle & $0.9^{\circ}, 1.8^{\circ}, 3.6^{\circ}, 5.4^{\circ}$ \\
\hline
\end{tabular}

model for granulation should be discussed. There are two models for the simulation of granulation process. One is trace movement of all particles. The other is trace movement of granulated particle only as one particle. The former might be better to analyze granulation mechanism. However, it is not realistic to simulate them because particles traced are enormous and it would take a long time to simulate the behavior of granules. Therefore the latter is adopted in this work. The assumptions in this simulation model are follows;

1) Granules are treated as one particle.

2) Particle shape is sphere.

3) Particle diameter is uniformly.

4) Particle diameter and other parameter is fixed in the simulation.

5) Effect of moisture is ignored.

Physical constants and simulation conditions are shown in Table 1.

\subsection{Continuous Drum Mixer}

Figure 2 shows the schematic diagram of a continuous drum mixer used in the simulation. Table 2 lists the size of drum mixer. Drum length and gradient angle were changed to investigate their effects on the granule behavior. The granules are fed at the extreme right of the drum mixer and granules drop from the extreme left (Fig. 2). Feeding rate is fixed at $100 \mathrm{~kg} / \mathrm{min}$.

\subsection{Determination of Parameters}

The simulation parameters are needed to be determined so that the granules behavior simulated correspond to the experimental results. Particularly the frictional coefficient has to be determined carefully since it strongly affects granules behavior. The simulation of granules behavior was per- (a)

(b)

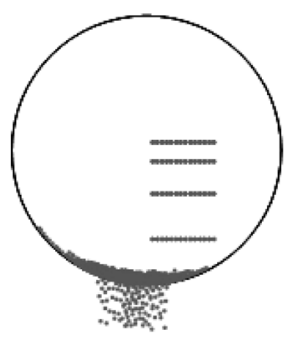

(c)

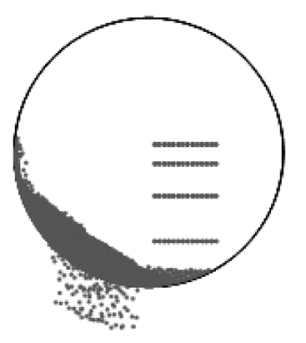

(d)
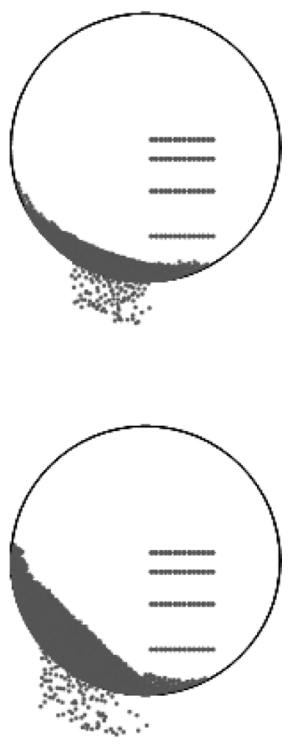

Fig. 3. Snapshot of granule motion in a continuous drum mixer at $120 \mathrm{~s}$ (frictional coefficient: (a) 0.1 ; (b) 0.3 ; (c) 0.5 ; (d) $0.7)$.

(a)

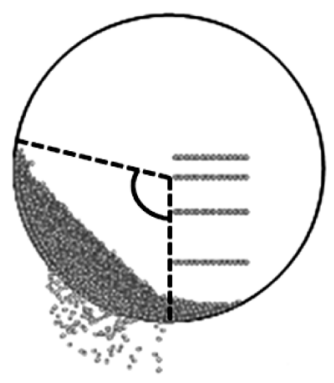

(b)

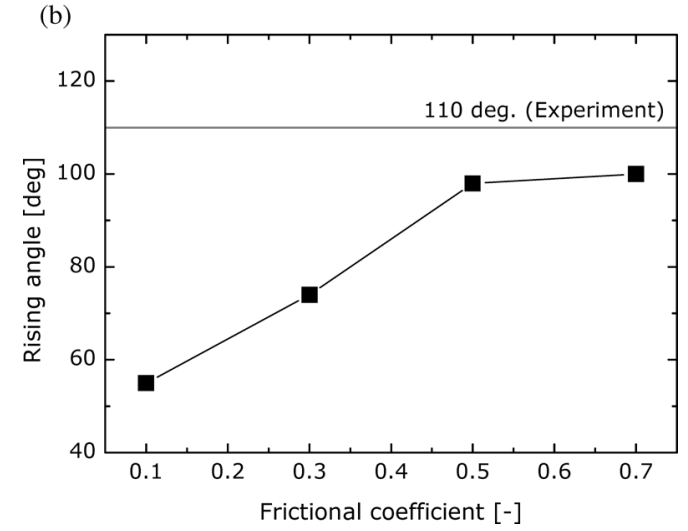

Fig. 4. (a) Definition of rising angle and (b) relationship between frictional coefficient and rising angle $(300 \mathrm{~cm}, n=20 \mathrm{rpm}$, $Q=100 \mathrm{~kg} / \mathrm{min}$ ).

formed to investigate the frictional coefficient on the behavior. The snapshots are shown in Fig. 3. The granules behavior is influenced by the frictional coefficient and a rising angle increases with an increase in the frictional coefficient. The rising angle was defined as shown in Fig. 4(a) to evaluate the granule behavior and to compare to experimental results. Figure 4(b) shows relationship between the friction coefficient used in the simulation and the rising angle. The rising angle obtained from the experiment was also shown in Fig. 3. The rising angle increases with an increase in the 
frictional coefficient until the coefficient is 0.5 , and then, the rising angle is going to be constant value about $100 \mathrm{de}-$ grees. The frictional coefficient was determined as 0.7 , at which the rising angle obtained from the simulation is the closest to experimental one, although the rising angle obtained from the simulation does not agree with experimental results completely. This difference between them could be due to the assumption of sphere in the granules. The reason of this difference will be investigated more detail in the future.

\section{Experiment}

Granulation experiment has been performed by using the continuous dram mixer. Granulator consists of rotating drum mixer, water nozzle and feed hopper (Fig. 5). The raw materials used in the actual process are supplied continuously at the extreme right of the drum mixer. Water is sprinkled by a nozzle, and granules are drained from the other end continually. The occupation ratio of iron ore in the drum mixer was measured, and also retention time were measured by mixing $\mathrm{ZnO}$ powder.

\section{Results and Discussion}

Figure 6 shows snapshots of granules motion in the

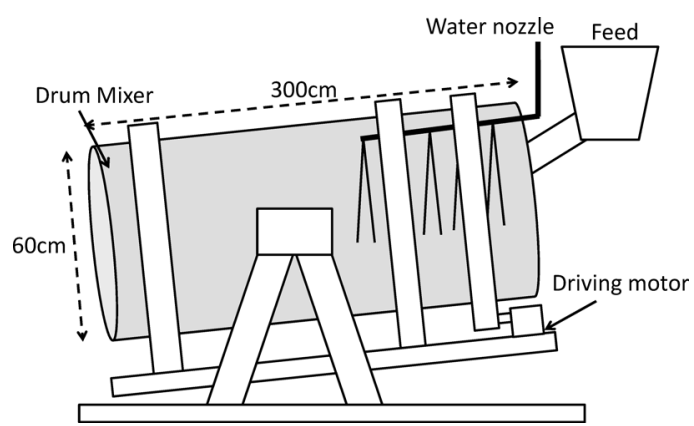

Fig. 5. Schematic diagram of the experiment.

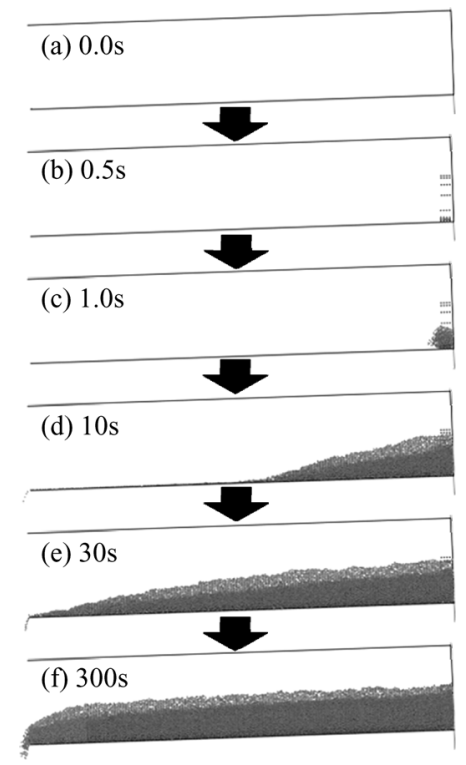

Fig. 6. Snapshot of granules motion in the drum mixer at different times $(Q=100 \mathrm{~kg} / \mathrm{min}, \alpha=1.8 \mathrm{deg}$., $300 \mathrm{~cm})$ : (a) $0.0 \mathrm{~s}$, (b) $0.5 \mathrm{~s}$, (c) $1.0 \mathrm{~s}$, (d) $10 \mathrm{~s}$, (e) $30 \mathrm{~s}$, and (f) $300 \mathrm{~s}$ drum mixer $(Q=100 \mathrm{~kg} / \mathrm{min}, \alpha=1.8 \mathrm{deg}$., $\phi 60 \times 300 \mathrm{~cm})$. The empty drum mixer was prepared as shown in Fig. 6(a), and then the granules are supplied at the extreme right continuously (Fig. 6(b)). They are moving to left (Figs. 6(c)-6(e)). A small amount of granules drops from the left edge (Figs. 6(d), 6(e)). The number of granules in the mixer increases little by little and the discharging rate of granules is going to be the same as the feeding rate. Finally the number of granules in the drum mixer is going to be constant (Fig. 6(f)).

\subsection{Effect of Gradient Angle}

Figure 7 shows number of granules in the drum mixer with time. The number of granules goes up rapidly in the initial stage, and then it is saturated in any cases. This state is called steady state. The number of granules in the drum mixer decreases as the gradient angle of the drum mixer increase. The time reaching the steady state becomes long with a decrease in the gradient angle of the drum mixer. The granules behavior in the term shown in the heavy line was analyzed.

Figure 8 shows the occupation ratio distributions in the direction of the rotational axis. Both simulation and experimental results were shown in Fig. 8. Regarding the experiment, in cases of higher gradient angle, it is seen that the occupation ratio is constant in the range from $50-300 \mathrm{~cm}$, and after this it decreases gradually toward the exit. On the other hand, in cases of lower gradient angle the occupation

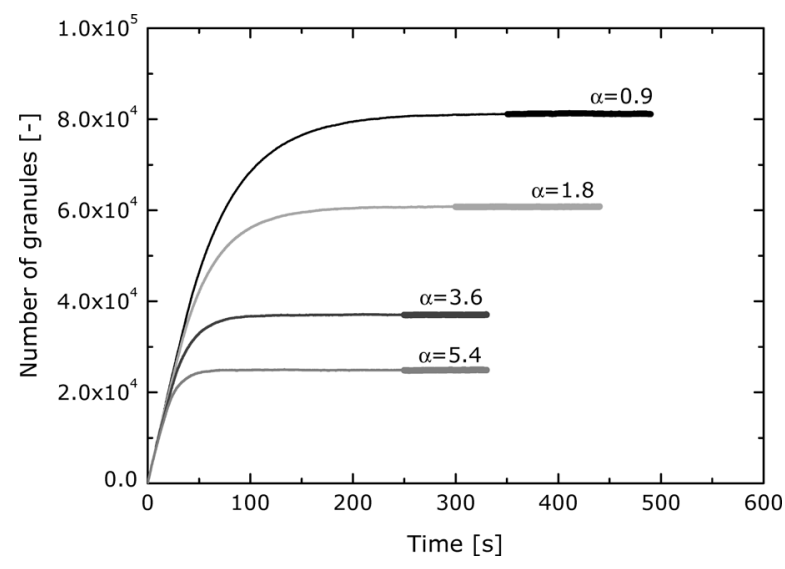

Fig. 7. Number of granules in the drum mixer as a function of time $(300 \mathrm{~cm}, Q=100 \mathrm{~kg} / \mathrm{min}, n=20 \mathrm{rpm})$.

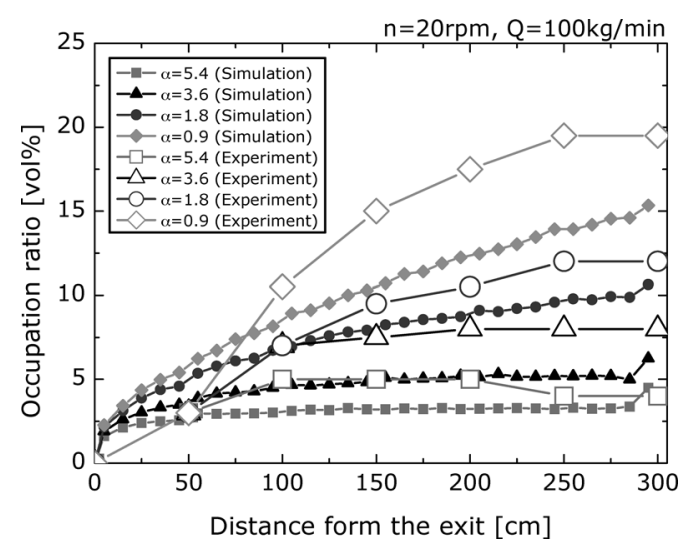

Fig. 8. Distributions of occupation ratio in the direction of rotating axis $(Q=100 \mathrm{~kg} / \mathrm{min}, n=20 \mathrm{rpm}, 300 \mathrm{~cm})$. 
(a)

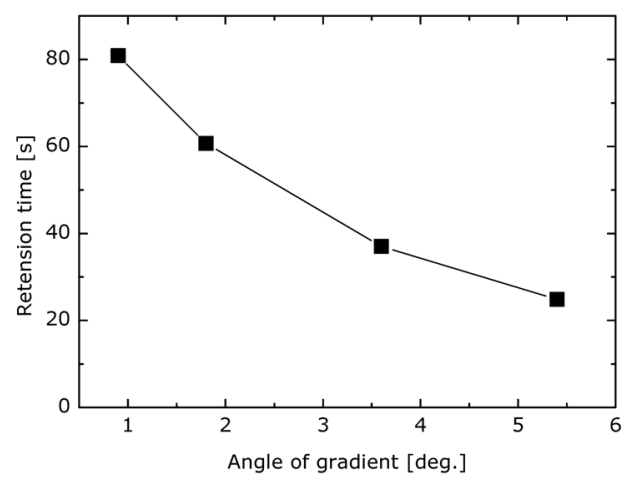

(b)

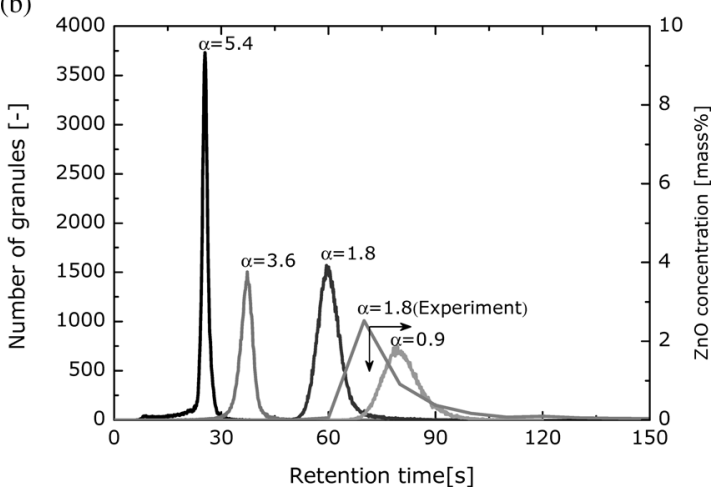

Fig. 9. (a) Retention time as a function of gradient angle and (b) retention time distribution $(Q=100 \mathrm{~kg} / \mathrm{min}, \alpha=1.8 \mathrm{deg}$., $n=20 \mathrm{rpm}, 300 \mathrm{~cm}$ ).

ratio gradually decreases from the feeding point. The same tendency can be seen in the simulation although the little differences between the simulation and experimental results could be seen quantitatively. The difference might be due to the assumption of non-change in granules size. Actually granule size is smaller in the feeding point and the granules are growing little by little toward the exit in the drum mixer. In general the flowability of smaller granules/particles is lower and that of larger granules is higher. Therefore, the occupation ratio in the experiment is larger than that in the simulation in the range of $50-300 \mathrm{~cm}$ and then experiment is smaller than that in the simulation in the range of $0-50 \mathrm{~cm}$.

Figure 9(a) shows relationship between (average) retention time and gradient of angle. Higher gradient angle gives longer retention time. Figure 9(b) shows retention time distribution as a parameter of gradient angle of the drum mixer. The retention time distribution is narrow when the gradient angle is low. As gradient angle becomes high, retention time distribution is going to be wider and shift to longer. The retention time obtained by the experiment was also shown in Fig. 9(b). The retention time obtained by simulation almost agrees with experimental results.

\subsection{Effect of Drum Mixer Length}

Figure 10 shows number of granules in the drum mixer with time as a parameter of drum mixer length. The number of granules increases quickly in the initial stage and then goes to be constant value. It takes longer time to reach the steady state when using longer length of the drum mixer. The granules behavior in the term shown in the heavy line was analyzed.

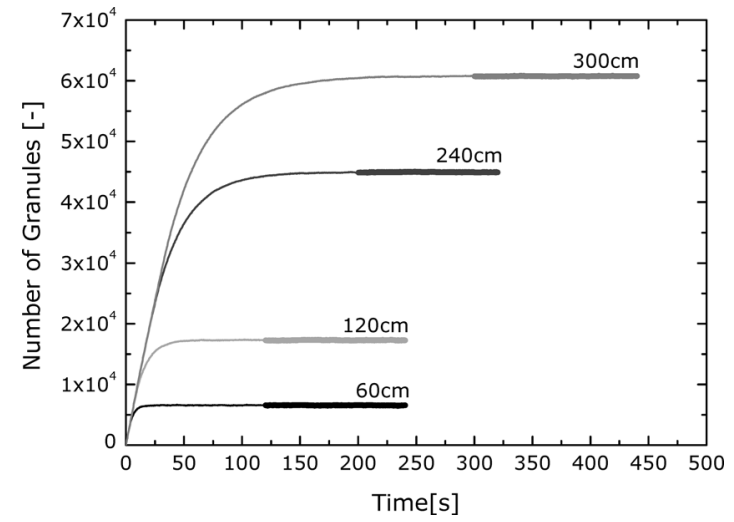

Fig. 10. Number of granules in the drum mixer as a function of time ( $\alpha=1.8 \mathrm{deg}$., $Q=100 \mathrm{~kg} / \mathrm{min}, n=20 \mathrm{rpm}$ ).

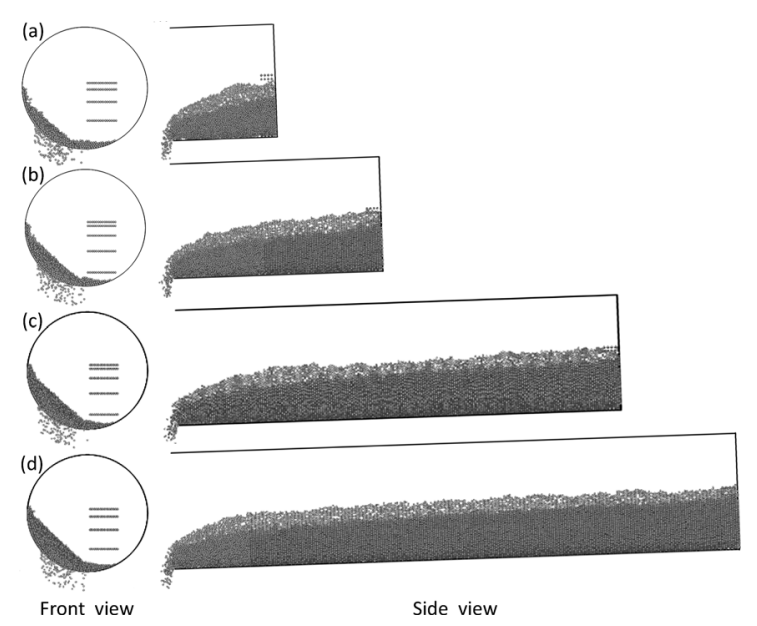

Fig. 11. Side and front view of drum mixer at steady state (a) $60 \mathrm{~cm}$; (b) $120 \mathrm{~cm}$; (c) $240 \mathrm{~cm}$; (d) $300 \mathrm{~cm}$.

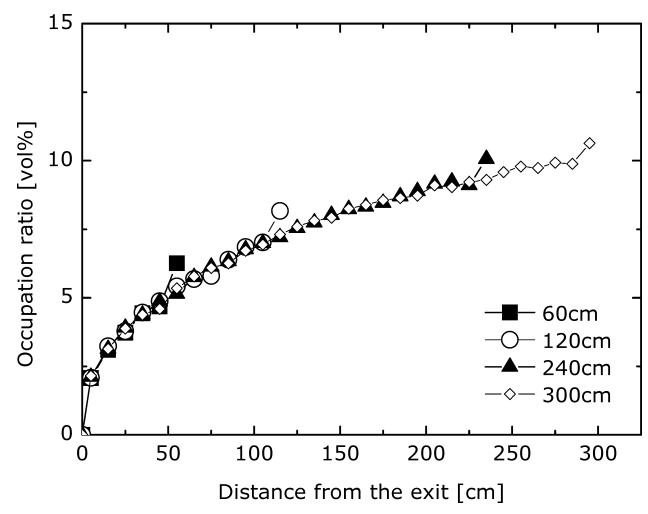

Fig. 12. Distributions of occupation ratio in the direction of rotating axis ( $Q=100 \mathrm{~kg} / \mathrm{min}, \alpha=1.8 \mathrm{deg}$., $n=20 \mathrm{rpm})$.

Figure 11 shows snapshots of the front view and side view of granules motion in the steady state in the drum mixer. No significant difference can not be seen according to the front view even if drum mixer length become long. While, the granule bed heights and its shapes are the almost the same in any cases.

Figure 12 shows the occupation ratio in the direction of rotational axis as a function of the distance from the exit which is a parameter of the length of the drum mixer. The occupation is getting smaller toward the exit from the feeding point and rapidly decreases near the exit. The difference 
(a)

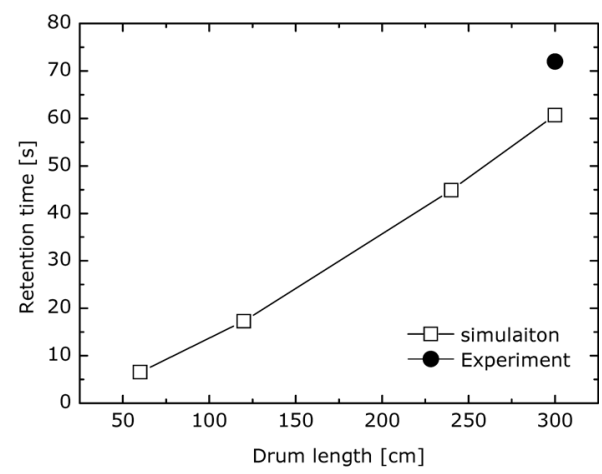

(b)

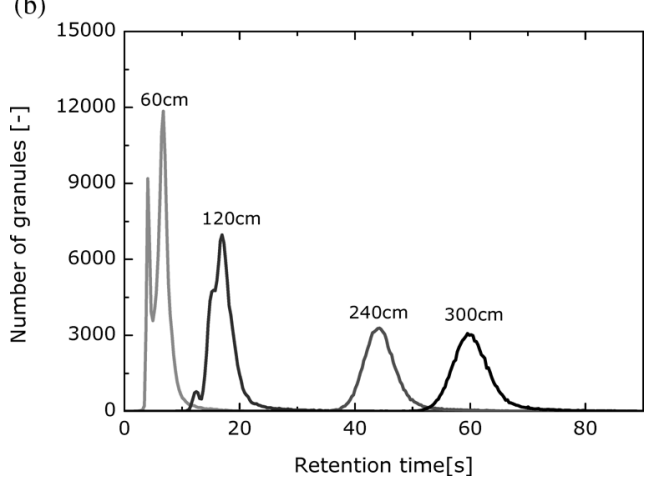

Fig. 13. (a) Relation between retention time and drum length and (b) distribution of retention time $(Q=100 \mathrm{~kg} / \mathrm{min}$, $\alpha=1.8$ deg., $n=20 \mathrm{rpm}, 300 \mathrm{~cm}$ ).

in the occupation ratio distributions can not be seen even if the drum mixer becomes longer. These results could be useful for optimum design of the drum mixer.

Figure 13(a) shows relationship between drum length and retention time. The retention time could be proportional to the drum length of the drum mixer. The simulation result is not so far from the experimental results.

Figure 13(b) shows retention time distribution with a parameter of the drum length. As the drum mixer length is shorter, the distribution of the retention time becomes narrower, and the retention time shifts toward shorter.

\section{Conclusion}

In order to analyze the motion of the raw materials of iron ore during granulation with a continuous drum mixer, a numerical simulation model was developed using the Discrete Element Method (DEM). Validity of the model was verified by comparing to the experimental results in terms of the occupation ratio and retention time of the granules. The simulation model will be useful to examine the granulation behavior of the raw materials, optimize the granulation parameters and design the efficient granulating equipments such as drum mixer and pan pelletizer.

\section{REFERENCES}

1) N. Sakamoto: ISIJ Int., 42 (2002), 834.

2) N. Ouchiyama and T. Tanaka: Ind. Eng. Chem. Process Des. Dev., 21 (1982), 29.

3) N. Ouchiyama and T. Tanaka: Ind. Eng. Chem. Process Des. Dev., 21 (1982), 35.

4) P. C. Kapur and D. W. Fuerstenau: Ind. Eng. Chem. Process Des. Dev., 21 (1982), 56.

5) M. Matsumura and T. Kawaguchi: Tetsu-to-Hagané, 87 (2001), 86.

6) Y. Hosotani, N. Konno, J. Shibata, T. Sato and H. Suzuki: Tetsu-toHagané, 81 (1995), 34.

7) Zouryu Handbook, ed. by The Association of Powder Process Industry and Engineering, Japan, O-mu-sha, Tokyo, (1991), 143.

8) I. Mekiguchi and H. Tohata: J. Chem. Eng., 32 (1968), 1012.

9) T. Ogawa, K. Ishino and Y. Sawahata: J. Soc. Powder Technol., 25 (1988), 150.

10) T. Ogawa, K. Ishino and Y. Sawahata: J. Soc. Powder Technol, 9 (1972), 153.

11) J. Kano, E. Kasai, F. Saito and T. Kawaguchi: ISIJ Int., 45 (2005), 500.

12) P. A. Cundall and O. D. L. Stack: Geotechnique, 29 (1979), 47.

13) H. Kiyama and H. Fujiyama: Proc. Jpn. Soc. Civ. Eng., 133 (1987).

14) Funtai Simyureishon Nyuumon, The Society of Powder Technology, Japan, Tokyo, (1998), 29.

15) J. Kano, F. Saito, A. Shimosaka and J. Hidaka: Kagaku Kogaku Ronbunshu, 18 (1995), 78.

16) J. Kano, F. Saito, A. Shimosaka and J. Hidaka: Kagaku Kogaku Ronbunshu, 23 (1997), 687.

17) J. Hidaka, J. Kano and A. Shimosaka: Kagaku Kogaku Ronbunshu, 18 (1995), 78.

18) T. Kawaguchi, T. Takeda and Y. Tsuji: Trans. Jpn. Soc. Mech. Eng. $B, 61$ (1995), 71.

19) S. Yuu, T. Abe, T. Saitoh and T. Umekage: Adv. Powder Technol., 6 (1996), 936.

20) B. K. Mishra and R. K. Rajamani: KONA, 8, (1990), 92.

21) J. Kano, F. Saito, A. Shimosaka and J. Hidaka: J. Chem. Eng. Jpn., 31 (1998), 936.

22) J. Kano and F. Saito: Powder Technol., 98 (1998), 166.

23) J. Kano, H. Mio and F. Saito: AIChE J., 46 (2000), 1964. 